\title{
CARACTERIZAÇÃO AGRONÔMICA DE GENÓTIPOS DE MILHO PARA A PRODUÇÃO DE SILAGEM
}

\author{
AGRONOMIC CHARACTERIZATION OF MAIZE GENOTYPES FOR SILAGE \\ Silva, M.R. ${ }^{\text {; }}$ Martin, T.N. ${ }^{2,3 *}$; Bertoncelli, P. ${ }^{3}$; Ortiz, S. ${ }^{4}$; Schmitz, T.H. ${ }^{4}$ e Vonz, D.S. ${ }^{4}$ \\ 'Programa de Pós-Graduação em Agronomia. Universidade Federal do Paraná. Curitiba-PR. Brasil. \\ ${ }^{2}$ Departamento de Fitotecnia. Universidade Federal de Santa Maria. Santa Maria-RS. Brasil. \\ *martin.ufsm@gmail.com \\ ${ }^{3}$ Programa de Pós-Graduação em Agronomia. Universidade Federal de Santa Maria. Santa Maria-RS. Brasil. \\ ${ }^{4}$ Universidade Tecnológica Federal do Paraná. Dois Vizinhos-PR. Brasil.
}

\section{PALAVRAS CHAVE ADICIONAIS}

Forragem. Matéria seca. Zea mays.

\section{RESUMO}

O objetivo deste trabalho foi avaliar às características agronômicas e a produtividade de seis genótipos de milho de ciclo super precoce quanto à produção de silagem no município de Dois Vizinhos, Paraná. O experimento foi conduzido na área experimental da Universidade Tecnológica Federal do Paraná. A altura média diferiu entre os cultivares, variando de 1,62 (Al-Piratininga) a 0,90 m (BMX 739). O híbrido AGN30A03 apresentou menor resistência ao acamamento de plantas e ao quebramento do colmo. Os genótipos BMX739, CD 304, PRE22T11 e Al-Piratininga obtiveram as maiores produtividades de massa verde $(638,81$; 455,$18 ; 620,98 ; 460,12$ g planta- $^{-1}$, respectivamente). A variedade Al-Piratininga apresentou número de espigas planta-1 $(1,11)$ superior ao das demais. Entre os materiais avaliados, o genótipo BMX 739 , se destacou pelo rendimento de matéria seca ensilável por área e pela participação percentual de espiga (29 \%) e grãos (26\%) na fitomassa.

\section{SUMMARY}

The aim of this work was to evaluate the agronomic characteristics and yield of six maize genotypes cycle super early in the production of silage in Dois Vizinhos, Paraná. The experiment was conducted at experimental area of the Universidade Tecnológica Federal do Paraná. The average height difference among cultivars, ranging from 1.62 (Al-Piratininga) to $0.90 \mathrm{~m}$ (BMX 739). The hybrid AGN30A03 showed less resistance to

\author{
AdDITIONAL KEYWORDS \\ Dry matter. Forage. Zea mays.
}

lodging of plants and culm breakage. The genotypes BMX 739, CD 304, PRE22T11 and Al-Piratininga obtained the highest yield of fresh forage (638.81, 455.18, 620.98, $460.12 \mathrm{~g} \mathrm{plant}^{-1}$, respectively). The variety Al-Piratininga presented a higher number of ears per plant $(1,11)$ than those of the other varieties. Among the materials tested, the genotype BMX 739, showed the highest dry matter yield per area and the percentage share of spike $(29 \%)$ and grains $(26 \%)$ in the phytomass.

\section{INTRODUÇÃO}

O milho é um dos principais produtos agrícolas da região sul do Brasil, pela sua contribuição na alimentação animal, onde entra como componente energético básico na fabricação de ração e na produção de silagem. Atualmente estão disponíveis 362 cultivares de milho convencionais (Cruz et al., 2009).

Dessa forma, o objetivo deste trabalho foi avaliar a produtividade e características agronômicas de seis genótipos de milho, no município de Dois Vizinhos, Paraná, visando à produção de silagem.

\section{MATERIALEMÉTODOS}

O experimento foi desenvolvido na área experimental da Universidade Tecnológica 


\section{SILVA, MARTIN, BERTONCELLI, ORTIZ, SCHMITZE VONZ}

Federal do Paraná, em Dois Vizinhos. A região é caracterizada pelo clima subtropical úmido mesotérmico (Cfa), segundo a classificação de Köppen (Maack, 1968) e o solo pertence à unidade de mapeamento Nitossolo Vermelho distroférrico úmbrico (Bhering e Santos, 2008).

O delineamento experimental utilizado foi em látice simples. Os tratamentos constituíram-se de seis genótipos de milho, fornecidos pela Embrapa Milho e Sorgo (Sete Lagoas, MG) (tabela I).

As parcelas, excluindo-se a bordadura, foram compostas por duas linhas de $5 \mathrm{~m}$ de comprimento, distanciadas a $90 \mathrm{~cm}$. A semeadura foi realizada no dia 08/10/2008, com posterior desbaste e ajuste para 50000 plantas por hectare. A adubação de base foi realizada com $250 \mathrm{~kg} \mathrm{ha}^{-1}$ da formulação comercial 10-20-20, e posteriormente foram aplicados $100 \mathrm{~kg} \mathrm{ha}^{-1}$ de nitrogênio em cobertura. Os tratos fitossanitários foram efetuados mediante aplicação de herbicidas e inseticidas, com produtos devidamente recomendados.

A germinação ocorreu no dia 18 de outubro de 2008 e as datas de colheita foram: 12, 20, 21 e 26 de janeiro de 2009, conforme o estádio de maturação dos grãos (32 à $35 \%$

Tabela I. Características agronômicas dos genótipos de milho do ensaio super precoce. (Agronomic characteristics of super early cycle corn genotypes).

\begin{tabular}{lccl}
\hline Genótipos & BG & DG & Empresa \\
\hline AGN30A03 & HS & SD & Agromen Tec. \\
BMX 739 & HT & SD & Biomatrix \\
CD 304 & HT & NI & Coodetec \\
PRE22T11 & HT & SD & Prezzotto \\
PRE22D11 & HD & SD & Prezzotto \\
AL-Piratininga & VAR & DM & DSMM/CATI
\end{tabular}

$B G=$ base genética: $H S=$ híbrido simples; $H T=$ híbrido triplo; $\mathrm{HD}=$ híbrido duplo; $\mathrm{VAR}=$ variedade; $D G=$ dureza do grão: $S D=$ semiduro; $N I=$ não informado; $\mathrm{DM}=$ dentado mole. de matéria seca). Avaliaram-se as seguintes características agronômicas: altura da planta; número de espiga planta ${ }^{-1}$; altura da espiga; produção de massa verde (g, planta); produção de massa seca (g, planta); número de plantas $\mathrm{ha}^{-1} \mathrm{e}$ as porcentagens de espiga, colmo e folha na massa seca (MS).

Os dados climáticos decendiais foram fornecidos pela estação climatológica automática (INMET).

Os resultados obtidos foram submetidos à análise da variância e a comparação de médias realizada pelo teste de DMS-t a $5 \%$ de significância.

\section{RESULTADOSEDISCUSSÃO}

Verificou-se que o ano agrícola 2008/ 2009 teve o segundo e terceiro decêndio de novembro, e o mês de dezembro, com precipitações abaixo da média (figura 1). Esse período coincide com o principal estádio de crescimento (8 a 20 folhas), desenvolvimento e diferenciação dos principais componentes de rendimento da cultura do milho, tornando-a sujeita a grandes impactos em termos de produção. Conforme relatado por Alvarez et al. (2006), nas gramíneas os colmos possuem baixo teor de proteína bruta e elevado teor de fibra em detergente ácido. Considerando que o colmo apresenta baixa qualidade nutricional o genótipo que apresentou menor participação desse componente na matéria seca foi o BMX 739 (24\%), sendo os maiores valores atribuídos ao PRE22T11 (42\%). No que diz respeito à participação percentual de folhas, o genótipo que se destacou foi o AlPiratininga, com $27 \%$ e os híbridos BMX 739 e CD 304 com menor participação (14\%). Santos et al. (2010), avaliando a porcentagem de espiga, folhas e colmo na massa seca, em condições climáticas favoráveis ao desenvolvimento da cultura, obtiveram variação de 33,9 a $21,1 \%$ para a fração colmo, 29,9 a $12,5 \%$ para o componente folha e 64,9 a $13,1 \%$ para espiga. Em relação à participação

Archivos de zootecnia vol. 63, núm. 242, p. 386. 


\section{CARACTERIZAÇÃO DE GENÓTIPOS DE MILHO PARA A PRODUÇÃO DE SILAGEM}

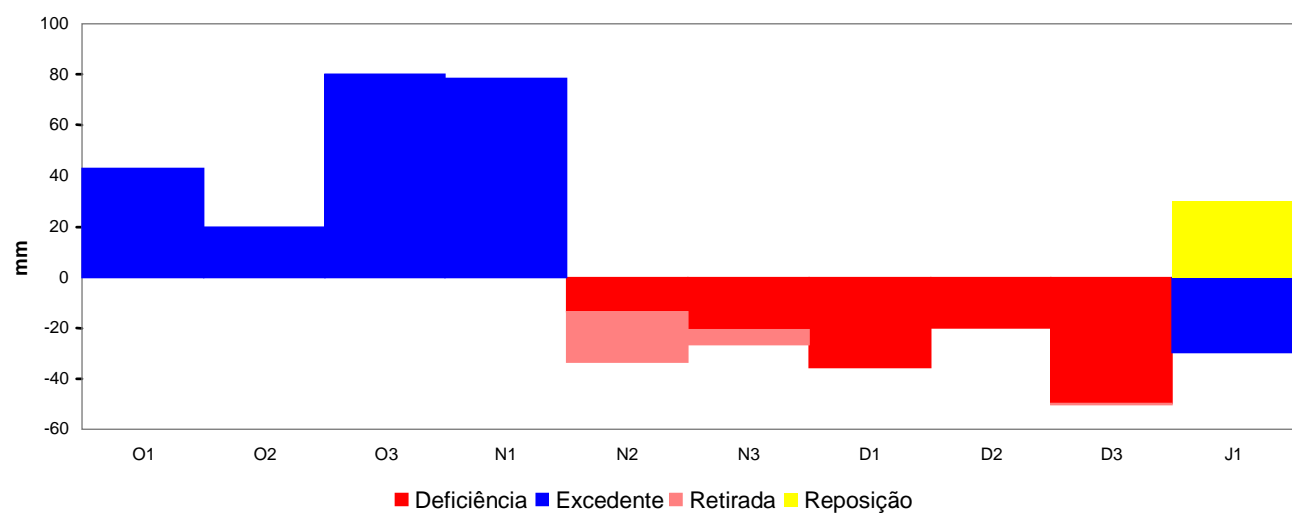

Figura 1. Balanço hídrico decendial indicando deficiência, excedente, retirada e reposição, adaptado de Rolim et al. (1998). (Decendial water balance, indicating the water deficit, surplus consumption and replacement, adapted from Rolim et al. (1998)).

do grão, que é o componente mais importante em função da concentração energética, constata-se que esta foi maior no BMX739 (26\%). A quantidade de grãos dos híbridos esteve abaixo dos $40 \%$ como o adequado para produção de volumoso com alta qualidade. Considerando-se que a cultura do milho é muito exigente em água, especialmente na época de florescimento e formação dos grãos e levando-se em conta a restrição hídrica observada no período de condução do trabalho, observou-se que a menor concentração de grãos foi no Al Piratininga (tabela II).

Conforme evidenciado por alguns autores quando restrições ambientais reduzem as taxas fotossintéticas e prejudicam a produção de fotoassimilados em quantidade

Tabela II. Participação percentual de espiga, colmo, folhas fotossinteticamente ativas e folhas senescentes de genótipos de milho do ciclo super precoce. (Proportions of cob, stalk, photosynthetically active and senescent leaves of super early cycle maize genotypes).

\begin{tabular}{|c|c|c|c|c|c|}
\hline \multirow[b]{2}{*}{ Genótipos } & \multirow[b]{2}{*}{ Colmo } & \multicolumn{3}{|c|}{$\%$ com base na matéria seca } & \multirow[b]{2}{*}{ Grãos } \\
\hline & & $\begin{array}{l}\text { Folhas fotossin- } \\
\text { teticamente ativas }\end{array}$ & $\begin{array}{c}\text { Folhas } \\
\text { senescentes }\end{array}$ & Espiga & \\
\hline AGN30A03 & $0,34^{\mathrm{abcd}}$ & $0,21^{a b c}$ & $0,09^{a b}$ & $0,20^{\mathrm{abcd}}$ & $0,14^{\mathrm{bcd}}$ \\
\hline BMX 739 & $0,24^{d}$ & $0,14^{d}$ & $0,05^{b}$ & $0,29^{a}$ & $0,26^{\mathrm{a}}$ \\
\hline CD 304 & $0,34^{\mathrm{abc}}$ & $0,19^{\text {bcd }}$ & $0,08^{\mathrm{ab}}$ & $0,21^{\text {abcd }}$ & $0,15^{\mathrm{abcd}}$ \\
\hline PRE22T11 & $0,42^{\mathrm{a}}$ & $0,17^{\mathrm{bcd}}$ & $0,08^{a b}$ & $0,19^{\mathrm{bcd}}$ & $0,13^{\mathrm{bcd}}$ \\
\hline PRE22D11 & $0,40^{\mathrm{ab}}$ & $0,23^{\mathrm{ab}}$ & $0,10^{\mathrm{ab}}$ & $0,13^{d}$ & $0,11^{\mathrm{cd}}$ \\
\hline AL-Piratininga & $0,39^{\mathrm{abc}}$ & $0,27^{a}$ & $0,12^{\mathrm{a}}$ & $0,14^{\mathrm{cd}}$ & $0,05^{d}$ \\
\hline Média & 0,35 & 0,29 & 0,08 & 0,19 & 0,14 \\
\hline CV & 18,64 & 18,69 & 40,5 & 21,60 & 30,47 \\
\hline DMS & 0,11 & 0,06 & 0,06 & 0,09 & 0,11 \\
\hline
\end{tabular}

a,b,c,dmédias não seguidas pela mesma letra na coluna diferem $(p<0,05)$ pelo teste de DMS-t. 


\section{SILVA, MARTIN, BERTONCELLI, ORTIZ, SCHMITZE VONZ}

suficiente para a manutenção dos tecidos, a maior demanda exercida pelos grãos por esses produtos leva os tecidos da raiz e da base do colmo à senescer precocemente (Fontoura et al., 2006).

Os genótipos avaliados apresentaram rendimento de matéria seca por planta entre 127,5 g (PRE 22D11) e 301,5 g (BMX 739) evidenciando o grande impacto do déficit hídrico sobre a produção biomassa da parte aérea. Apesar de considerar-se um elevado teor de matéria seca, individualmente atingindo em média a 41,82\% (213,1/509,5), a produção média de matéria seca por área foi de $8598,5 \mathrm{~kg} \mathrm{ha}^{-1}$ (213,1 $\mathrm{g} \mathrm{x} 40350$ plantas). Conforme evidenciado por alguns autores o rendimento de matéria seca da cultura do milho atingiu $13700 \mathrm{~kg} \mathrm{ha}^{-1}$ (Santos et al., 2010), em se considerando condições

\section{BIBLIOGRAFIA}

Alvarez, C.G.D.; Pinho, R.G.V.e Borges, I.D. 2006. Avaliação de características bromatológicas da forragem de milho em diferentes densidades de semedura e espaçamentos entre linhas. Ciênc Agrotec, 30: 409-414.

Bhering, S.B. e Santos, H.G. 2008. Mapa de solos do Estado do Paraná: legenda atualizada. EMBRAPA/IAPAR. Rio de Janeiro. 74 pp.

Cruz, C.C.; Perreira Filho, I.A. e Silva, G.H. 2009. Milho: Cultivares para 2008/2009. <http:// www.cnpms.embrapa.br/milho/cultivares/ index.php> (07/12/2010).

Fontoura, D.; Stangarlin, J.R.; Trautmann, R.R.; Schirmer, R.; Schwantes, D.O. e Andreotti, M. 2006. Influência da população de plantas na incidência dedoenças de colmo em híbridos de milho na safrinha. Acta Sci Agron, 28: 545-551.

Maack, R. 1968. Geografia física do Estado do hídricas menos drásticas. Da mesma forma, Pinto et al. (2010), relataram uma produção de matéria seca por planta de $400 \mathrm{~g}$ a $270 \mathrm{~g}$, com produtividade de $20,6 \mathrm{tha}^{-1}$ a $16,4 \mathrm{tha}^{-1}$.

\section{CONCLUSÕES}

Os híbridos BMX 739, CD 304,PRE22T11 e a variedade Al-Piratininga obtiveram as maiores produtividades de massa verde $\left(638,81 ; 455,18 ; 620,98\right.$ e 460, 12 g planta $^{-1}$, respectivamente). O genótipo AGN30A03 apresentou maior tendência ao acamamento de plantas e ao quebramento do colmo. Entre os materiais testados destaca-se o híbrido BMX 739 pela produção de matéria seca ensilável por área e pela participação percentual de espigas (29\%) e grãos $(26 \%)$ na fitomassa.

Paraná. Banco do Desenvolvimento do Paraná. Curitiba. 350 pp.

Pinto, A.P.; Lançanova, J.A.C.; Lugão, S.M.B.; Roque, A.R.; Abrahão, J.J.S.; Oliveira, J.S.; Leme, M.C.J. e Mizubuti, I.Y. 2010. Avaliação de doze cultivares de milho (Zea mays L.) para silagem. Semina: Ciências Agrárias, 31: 10711078.

Rolim, G.S.; Sentelhas, P.C. e Barbieri, V. 1998. Planilhas no ambiente ExcelTM para cálculos de balanços hídricos: normal, seqüencial, de cultura e de produtividade real e potencial. $R B A, 6$ : 133-137.

Santos, R.D.; Perreira, L.G.R.; Neves, A.L.A.; Azevedo, A.G.; Moraes, S.A. e Costa, C.T.F. 2010. Características agronômicas de variedades de milho para produção de silagem. Acta Sci Anim Sci, 32: 367-373. 